\title{
ADOPSI TEKNIK PENYUSUNAN BUSINESS PLAN MODEL CANVAS UNTUK PERENCANAAN BISNIS UMKM KULINER JALANAN DI KAWASAN GATOT SUBROTO BANJARMASIN
}

\author{
Rizka Zulfikar $^{1]}$, Prihatini Ade Mayvita ${ }^{2]}$, Purboyo ${ }^{3]}$, dan Syahrani ${ }^{4]}$ \\ Fakultas Ekonomi, Universitas Islam Kalimantan \\ Email : ${ }^{1]}$ rizkazulfikar@gmail.com, ${ }^{2]}$ ademayvita@gmail.com, \\ ${ }^{3]}$ mail.purboyo@gmail.com, ${ }^{4]}$ mmsyahrani@gmail.com
}

\begin{abstract}
ABSTRAK
UMKM kuliner jalanan cenderung memiliki tingkat persaingan yang tinggi karena entry barrier usaha yang rendah. Oleh karena itu UMKM kuliner jalanan harus memiliki perencanaan dan strategi bisnis yang baik agar bisa memenangkan persaingan di antara usaha sejenis. Kegiatan pengabdian masyarakat ini dilaksanakan dalam 3 tahap kegiatan yaitu : (1) tahap persiapan, (2) tahap pelaksanaan dan (3) tahap evaluasi. Tahap pelaksanaan dilakukan tanggal 22 Desember 2018 bertempat d Rumah Makan Ayam Kudus di Jalan Gatot Subroto dalam bentuk pelatihan dengan jumlah peserta terdiri dari 10 (sepuluh) UMKM kuliner jalanan di kawasan Gatot Subroto Banjarmasin. Kegiatan ini memiliki tujuan untuk : (1) Memberikan pengetahuan kepada mitra tentang arti pentingnya value propositions yang harus dimiliki agar usaha mitra nantinya memiliki value yang berbeda dengan usaha lain yang sejenis, (2) Memberikan keterampilan pembuatan rencana bisnis dengan mengadopsi teknik business plan model canvas yang dapat dipraktekkan mitra dalam menjalankan usahanya, (3) Memberikan pengetahuan kepada mitra tentang penyusunan strategi bisnis yang baik. Hasil pelaksanaan kegiatan diantaranya adalah : (1) $30 \%$ peserta mampu membuat business plan model canvas secara baik dan benar, (2) $20 \%$ peserta sudah dapat menentukan komponen value propositions namun masih kesulitan dalam membuat business plan secara keseluruhan, (3) 50\% peserta masih belum mampu menentukan komponen value propositions dan membuat business plan secara keseluruhan. Untuk peserta yang sudah dapat menentukan komponen value propositions, kemudian ditindak lanjuti dengan melaksanakan kunjungan ke lokasi mitra dan dibimbing secara khusus untuk membuat business plan secara lengkap. Hasil evaluasi kinerja kegiatan adalah mayoritas peserta memberikan penilaian sangat baik kepada kemampuan pembicara dalam menyampaikan materi, isi materi, suasana pelatihan serta sarana dan prasarana.
\end{abstract}

Kata kunci: business plan model canvas, value propositions, UMKM.

\section{PENDAHULUAN}

Hampir di setiap kota besar di Indonesia, bisnis kuliner jalanan (street food) atau sering juga disebut pedagang kaki lima (PKL) makanan selalu bisa dijumpai dengan mudah. Bahkan beberapa kota besar telah menjadikan bisnis kuliner jalanan menjadi bagian dari kegiatan pariwisata kota yang terus dikembangkan untuk menarik minat pendatang baik dari luar maupun dalam negeri, sehingga tidak dapat dipungkiri 
bahwa UMKM (Usaha Mikro Kecil Menengah) di bisnis ini memiliki peranan yang cukup penting bagi perkembangan perekonomian suatu daerah.

Keberadaan UMKM kuliner jalanan ini merupakan salah satu dampak dari kurangnya lapangan kerja sektor formal di Indonesia yang memaksa sebagian besar masyarakatnya bekerja di sektor informal. Bahkan munculnya bisnis ini dapat dianggap sebagai bentuk upaya masyarakat untuk mengurangi tingkat pengangguran di suatu daerah atau kota (Satrya, 2010).

Karakteristik umum dari bisnis kuliner jalanan ini adalah usaha berjualan produk makanan yang dilakukan secara temporer, fleksibel, compact dan simple, bisnis ini seringkali dikategorikan sebagai suatu usaha kecil-mikro karena lingkup usahanya (Sustiana, 2012). Meskipun tidak semua masyarakat menerima dengan baik keberadaan bisnis ini, namun sebenarnya bisnis di bidang kuliner jalanan ini memiliki potensi untuk berkembang jika didukung, dibina dengan baik dan optimal.

Beberapa hambatan yang seringkali dihadapi oleh UMKM kuliner jalanan antara lain adalah ketergantungan yang besar pada pelanggan, kurangnya keterampilan dan pengetahuan yang diperoleh melalui pelatihan baik mengenai proses produksi, kualitas pelayanan dan produk, sanitasi dan hygienis produk serta rendahnya sikap belajar dan membangun jaringan karena tradisi mereka untuk bekerja sendiri (Laforet dan Tann, 2006) dan seringkali mereka tidak terlalu memperhatikan metode perencanaan dan pengawasan. Kapasitas kompetitif usaha kecil sangat kurang yang dapat mempengaruhi penjualan dan tidak dapat menunjukkan prestasi yang baik karena kurangnya praktek dan strategi yang mereka gunakan (Vaaland dan Heide, 2007). Usaha berskala kecil (UMKM) secara umum lemah dalam hal perencanaan bisnis, tidak memiliki model bisnis dan perencanaan strategis (Carvalho dan Jonker, 2015). Usaha berskala kecil memiliki keragaman dalam hal kegiatan usaha meskipun output yang dihasilkan sama dan hal ini tentunya akan menimbulkan berbagai macam model bisnis, sehingga untuk usaha kecil seringkali tidak dapat dijelaskan hanya oleh satu model bisnis (Lindgren, 2013). 
UMKM kuliner jalanan umumnya memposisikan diri sebagai follower dengan mengadopsi produk yang telah berhasil di pasar dan cenderung menggunakan strategi penetration price sebagai nilai tambah usaha mereka (Swasty, 2015). Dalam jangka pendek strategi ini akan berhasil, namun strategi ini tidak akan menjamin keberhasilan yang sama di masa depan. Maka, konsep ini sebenarnya tidak relevan untuk kedepannya, apalagi daya beli masyarakat yang terus meningkat membuat sisi harga bukan lagi prioritas konsumen (Kurniawan, 2012). Oleh karena itu UMKM kuliner harus memiliki strategi pemasaran yang baik agar bisa memenangkan persaingan di antara usaha sejenis (Purnomo, 2017).

Di kota Banjarmasin, ada beberapa kawasan atau jalan yang dipenuhi oleh bisnis kuliner jalanan ini. Salah satunya adalah Jalan Gatot Subroto yang cukup ramai karena jalan ini merupakan salah satu jalan penghubung antara jalan A. Yani dengan Jalan Veteran dengan tingkat kepadatan lalu lintas dan jumlah potensi usaha di kawasan ini yang cukup banyak. Keberadaan usaha kuliner jalanan di kawasan ini semakin berkembang seiring dengan kegiatan Dinas Tata Kota Banjarmasin yang menjadikan kawasan ini sebagai jalan protokol kelas II kota Banjarmasin. Di sepanjang jalan ini setidaknya terdapat puluhan bisnis kuliner jalanan yang menjajakan produk makanan seperti nasi \& mie goreng, burger, gorengan, empek-empek, pisang goreng dan sebagainya.

Adapun UMKM kuliner jalanan yang dijadikan mitra dalam kegiatan pengabdian kepada masyarakat ini adalah UMKM yang menjalankan usaha kulinernya di sepanjang jalan Gatot Subroto dengan berbagai macam jenis output produk.

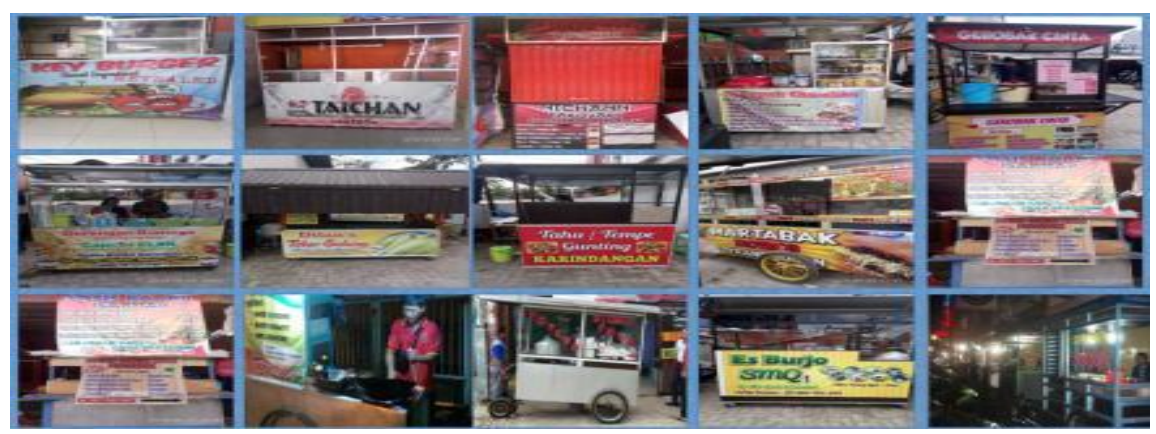

Gambar 1. UMKM kuliner jalanan di kawasan Gatot Subroto Banjarmasin 
Tujuan kegiatan pengabdian kepada masyarakat ini adalah Memberikan pengetahuan kepada para UMKM tentang arti pentingnya value propositions (nilai produk yang akan ditawarkan) agar usaha mitra memiliki value yang berbeda dengan usaha lain yang sejenis dan mampu bertahan dari tingginya tingkat persaingan, Memberikan keterampilan pembuatan rencana bisnis dengan mengadopsi business plan model canvas yang nantinya dapat dipraktekkan mitra dalam menjalankan usahanya dan (3) Memberikan pengetahuan kepada mitra kegiatan tentang penyusunan strategi bisnis yang baik.

\section{METODE KEGIATAN}

Kegiatan pengabdian kepada masyarakat ini dilaksanakan pada bulan Desember 2018, dimana metode pelaksanaan kegiatan ini dilakukan dalam 3 tahapan yaitu (1) tahap persiapan (2) tahap kegiatan, dan (3) tahap pendampingan Tahap persiapan dilakukan dengan mengadakan survey pendahuluan ke lokasi mitra. Survei dilakukan untuk mengetahui kesediaan mitra untuk bekerjasama dengan tim pengusul dan untuk mengetahui permasalahan mitra, menetapkan solusi bersama yang akan dilaksanakan dan waktu pelaksanaan. Khalayak sasaran dari kegiatan ini adalah 10 UMKM kuliner jalanan yang ada di kawasan Gatot Subroto.

Tahap kegiatan berisikan kegiatan-kegiatan seperti pelatihan pembuatan business plan model canvas. Sedangkan tahap pendampingan berisikan kegiatan pendampingan dalam penyusunan rencana bisnis mitra.

Penyusunan perencanaan bisnis mitra mengadopsi teknik business plan model canvas, karena teknik ini merupakan salah satu metode paling sederhana dalam menetapkan rencana bisnis dan dapat digunakan oleh UMKM dalam penyusunan rencana bisnisnya. Business plan Model Canvas (BMC) seringkali digunakan oleh pebisnis dalam merencanakan suatu usaha baru (start up), namun model ini juga digunakan oleh para pelaku usaha yang sedang menjalankan usahanya (Strategyzer.com, 2012). Model ini juga dipakai untuk memvalidasi jalannnya usaha yang sedang dijalankan apakah telah sesuai dengan rencana awal pada saat memulai usaha dengan mempertimbangkan kondisi internal dan eksternal yang ada (Osterwalder et al., 2010). 
Business plan model canvas terdiri dari 9 komponen utama pendorong keberhasilan suatu bisnis dan tergabung dalam 1 kanvas (Osterwalder et al., 2010). Kesembilan komponen tersebut antara lain adalah :

1. Customer Segments : yaitu kegiatan menentukan segmen target customer dari bisnis yang akan dikembangkan Siapa yang akan ditargetkan menjadi konsumen dan seperti apa deskripsi dan bagaimana karakteristik mereka? Apa yang mereka pikirkan, rasakan dan akan lakukan?.

2. Value Proposition : yaitu kegiatan memperkirakan kebutuhan customer yang sudah diidentifikasi pada customer segment. Berdasarkan kebutuhan itu, selanjutnya dapat didefinisikan value (nilai) apa yang akan diberikan agar mampu memenuhi kebutuhan customer. Pertanyaan yang harus dijawab adalah solusi atau produk apa yang dapat ditawarkan ke konsumen Apa yang menarik dari produk yang ditawarkan? Apa yang membuat konsumen mau memilih, membeli, dan menggunakan value usaha kita? (Fauvel, 2013). Menawarkan produk dengan value yang setara namun dengan harga lebih rendah adalah cara umum untuk memenuhi kebutuhan segmen pelanggan yang sensitif terhadap harga (Osterwalder et al., 2010).

3. Channels : yaitu cara untuk mencapai customer. Channel ini adalah jalur antara perusahaan dengan customer dan pertanyaan yang harus dijawab adalah bagaimana delivery dari value yang diberikan akan mampu mencapai customer dengan baik. Pertanyaan yang harus dijawab adalah Bagaimana cara agar value / solusi /produk bisa sampai ke tangan konsumen?

4. Customer Relationship : yaitu mendefinisikan hubungan antara perusahaan dan customer. Macammacam jenis hubungan mulai dari memberikan bantuan personal perorangan kepada setiap customer, dengan memanfaatkan komunitas, atau bahkan berupa 'self-service', yaitu tidak berhubungan langsung dengan customer. Pertanyaan yang harus dijawab bagaimana cara kita berinteraksi untuk menjaga loyalitas konsumen?

5. Revenue Streams : yaitu 
representasi dari jalur penerimaan uang yang akan diterima dari setiap customer segment. Pertanyaan yang harus dijawab adalah Bagaimana cara bisnis menghasilkan uang dari value /solusi/produk yang ditawarkan?

6. Key Activities : adalah kegiatan utama yang menjelaskan hal terpenting yaitu perusahaan harus membuat model bisnis. Setiap model bisnis dibuat untuk sejumlah Kegiatan Utama. Hal ini merupakan tindakan yang paling penting bagi perusahaan sehingga harus maksimal untuk dapat menghasilkan operasi yang berhasil. Pertanyaan yang harus dijawab adalah Apakah aktivitas kunci atau strategi kompetitif yang dilakukan bisnis untuk menciptakan value proposition nya?

7. Key Resources : adalah sumber daya utama yang menjelaskan mengenai aset terpenting yang diperlukan dalam membuat model bisnis kerja. Setiap model bisnis memerlukan sumber daya utama. Pertanyaan yang harus dijawab adalah apa saja sumber daya yang harus dimiliki agar dapat kompetitif dalam menciptakan value/solusi/produk?

(Swasty, 2015).

8. Key Partnership : adalah kunci kemitraan yang menjelaskan jaringan pemasok dan mitra yang membuat pekerjaan model bisnis. Perusahaan menjalin kemitraan untuk berbagai alasan, dan kemitraan menjadi landasan model bisnis. Ada empat jenis kemitraan :

- Strategi aliansi antara nonpesaing

- Strategi kemitraan antara pesaing (Coopetition)

- Usaha bersama: usaha untuk mengembangkan bisnis baru

- Hubungan Pembeli-Pemasok untuk menjamin pasokan yang dapat diandalkan.

9. Cost Structure : adalah struktur biaya yang menggambarkan semua biaya yang dikeluarkan dalam mengoperasikan model bisnis ini. Blok bangunan ini menjelaskan biaya yang paling besar terjadi antara biaya-biaya yang harus dikeluarkan untuk dapat menghasilkan value proposition yang ditujukanpada customer segments sehingga didapat revenue stream. Biaya tersebut dapat dihitung relatif mudah setelah 
mendefinisikan sumber daya utama,

kegiatan utama, dan kunci

kemitraan. merupakan contoh business model canvas, yang terdiri dari 9 komponen utama dalam bisnis.

Gambar 3 berikut ini

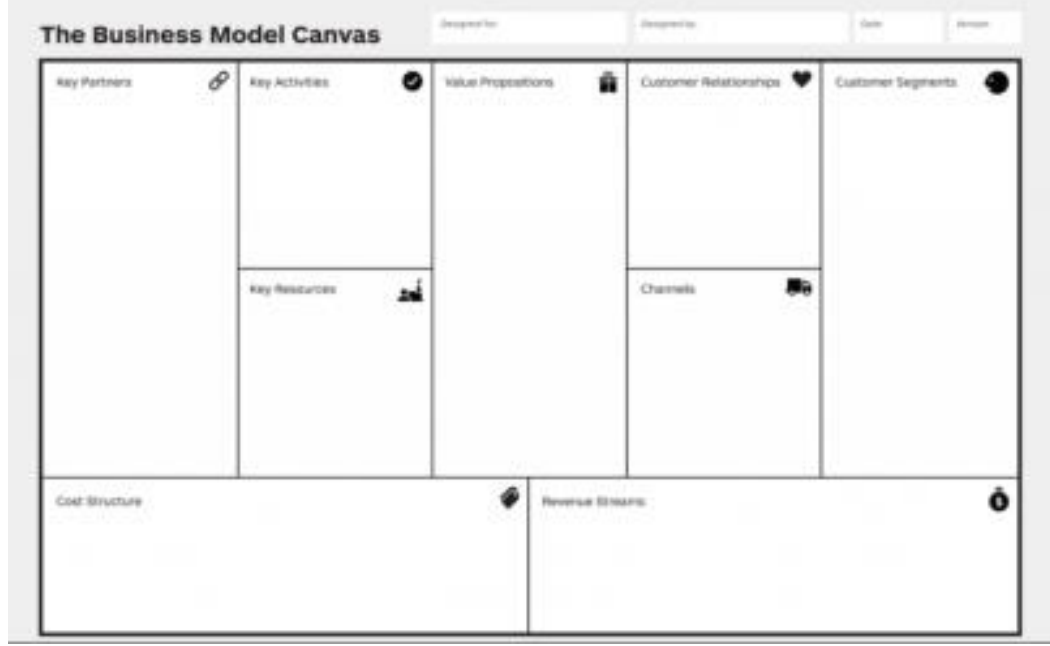

Gambar 2. Business Plan Model Canvas (Osterwalder et al.,2010)

Secara sederhana, teknik BMC ini sebenarnya terdiri dari 3 bagian utama yaitu offering, customer dan infrastructure (Swasty, 2015). Adapun gambar pembagian hal tersebut adalah sebagai berikut :

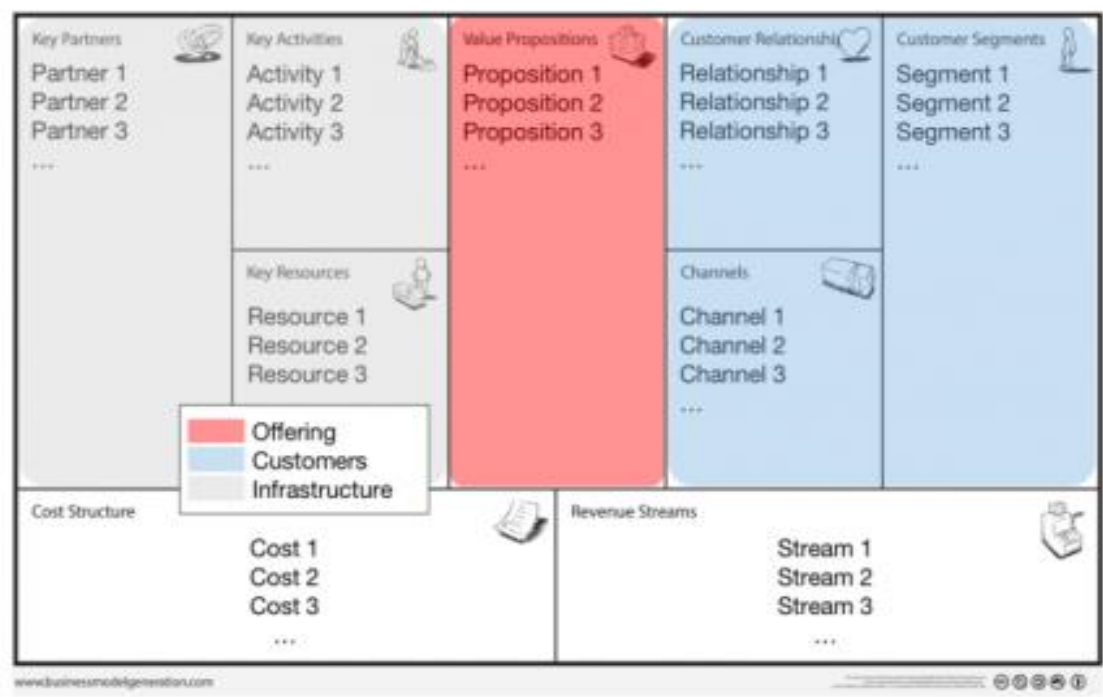

Gambar 3. Komponen utama BMC (Osterwalder et al.,2010) 


\section{HASIL KEGIATAN DAN LUARAN}

\section{A. Tahap Persiapan}

Pada tahap Persiapan dilakukan dalam 2 (dua) kali pertemuan yakni

1. Pertemuan pertama dilakukan pada tanggal 8 Desember 2018 dengan mendatangi lokasi usaha mitra yang akan diundang dalam kegiatan.

2. Pertemuan kedua pada tanggal 18 Desember 2018 untuk memastikan waktu pelaksanaan dan tempat pelaksanaan kegiatan.

\section{B. Waktu, Tempat dan Peserta}

\section{Kegiatan}

Kegiatan pengabdian kepada masyarakat ini dilaksanakan pada tanggal 22 Desember 2018 yang dimulai pada pukul 09.00 sampai dengan pukul 12.30 WITA, bertempat di Rumah Makan Ayam Kudus yang beralamat di Jalan Raya Gatot Subroto yang diikuti oleh 10 UMKM kuliner jalanan yang melaksanakan usaha di kawasan gatot subroto Banjarmasin. Kegiatan pengabdian kepada masyarakat ini dihadiri oleh Wakil Dekan III Fakultas Ekonomi Universitas Islam Kalimantan MAB Banjarmasin yakni Bapak Syahrani, SE, MM untuk memberikan kata sambutan sekaligus membuka secara resmi kegiatan.

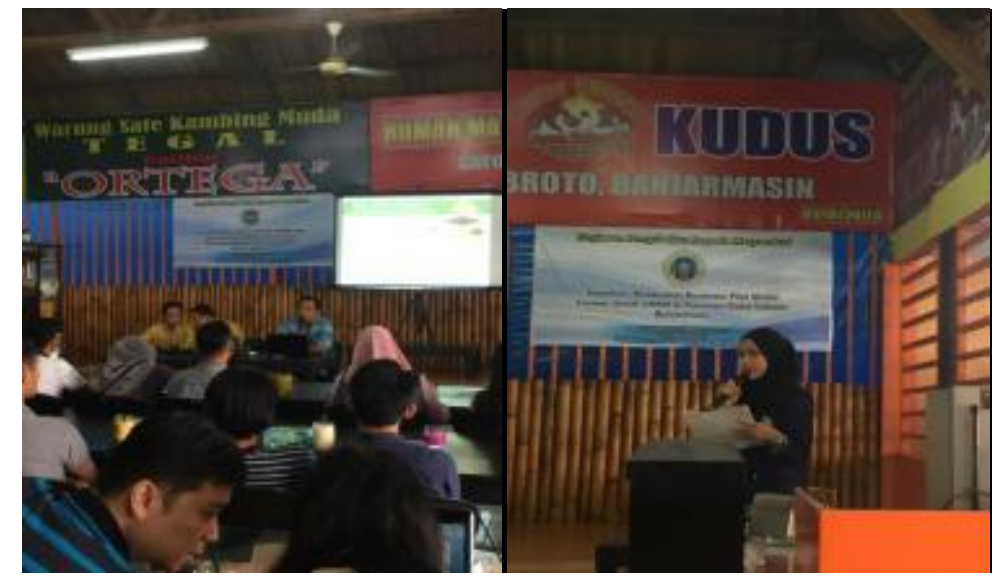

Gambar 4. Acara Pembukaan Kegiatan 


\section{Tahap Pelaksanaan}

Pelaksanaan

kegiatan

dilakukan dengan beberapa metode yakni metode ceramah dan diskusi serta pelatihan pembuatan business plan model canvas.

\section{1) Ceramah dan Diskusi}

Dalam ceramah dan diskusi disampaikan komponen-komponen penting dalam penyusunan business plan model canvas.
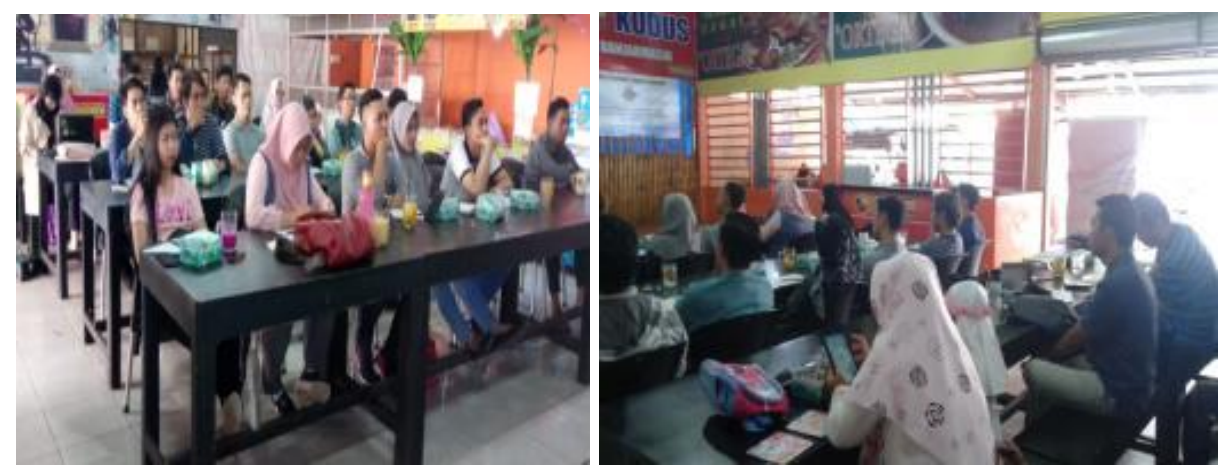

Gambar 5. Peserta Kegiatan

\section{2) Tahap Pelatihan}

Pada tahap pelatihan ini, seluruh peserta diminta untuk mengisi komponen-komponen yang ada dalam business plan model canvas sesuai dengan karakteristik usahanya masingmasing. Dalam pelaksanaan tahap pelatihan ini, hasil yang didapat antara lain adalah : (a) $30 \%$ peserta atau sebanyak 3 UMKM mampu membuat business plan model canvas secara baik dan benar. Contoh hasil business plan model canvas peserta yang telah lengkap disajikan pada gambar berikut ini : 


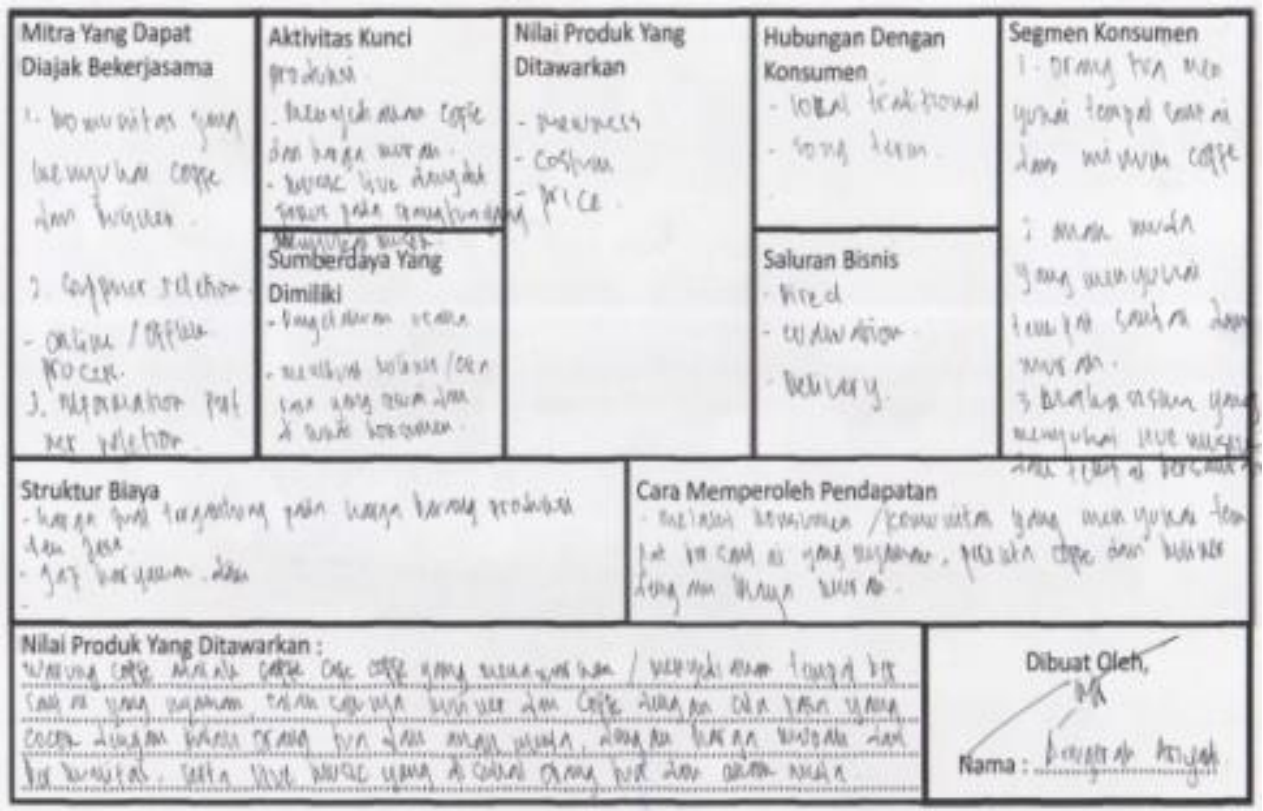

\section{Gambar 6. Business Plan Model Canvas UMKM Cafe Coffe Anugerah}

(b) $20 \%$ peserta atau sebanyak 2 UMKM sudah dapat menentukan komponen value propositions namun masih kesulitan dalam membuat business plan secara keseluruhan. Contoh hasil business plan model canvas peserta yang telah dapat menentukan value propositions namun belum bisa membuat business plan secara lengkap disajikan pada gambar berikut ini

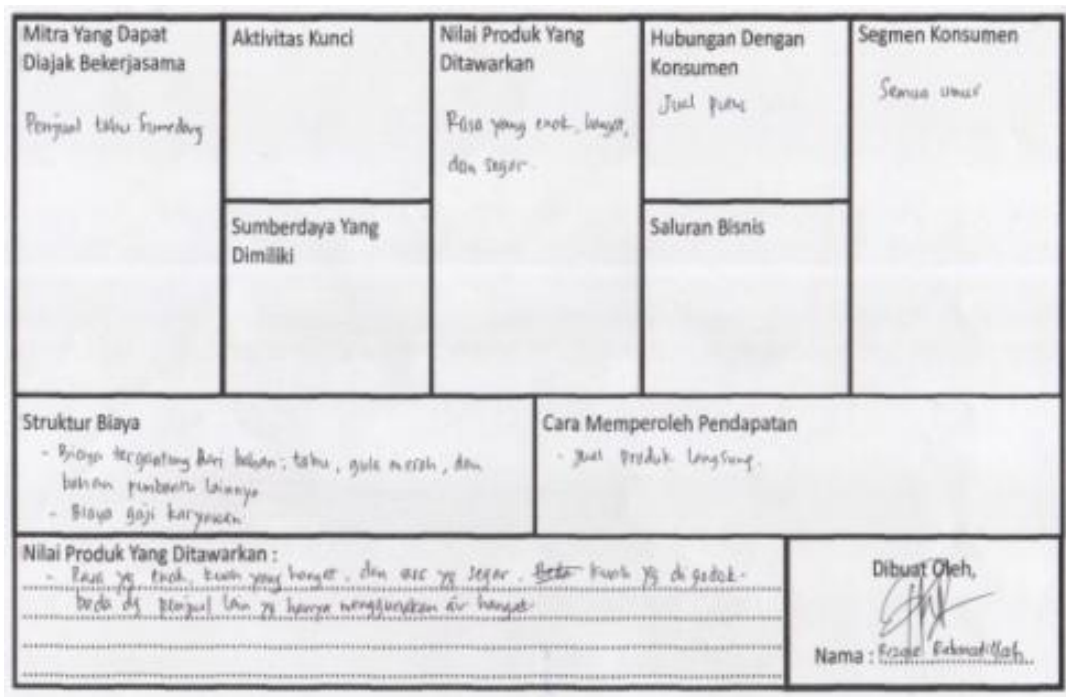

Gambar 7. Business Plan Model Canvas UMKM Tahu Gejrot 
(c) $50 \%$ peserta atau atau sebanyak 50 UMKM masih belum mampu menentukan komponen value propositions dan membuat business plan secara keseluruhan.

Untuk peserta yang sudah dapat menentukan komponen value propositions, kemudian ditindak lanjuti dengan melaksanakan kunjungan ke lokasi mitra pada tanggal 3 Januari 2018 dan dibimbing secara khusus untuk membuat business plan secara lengkap.

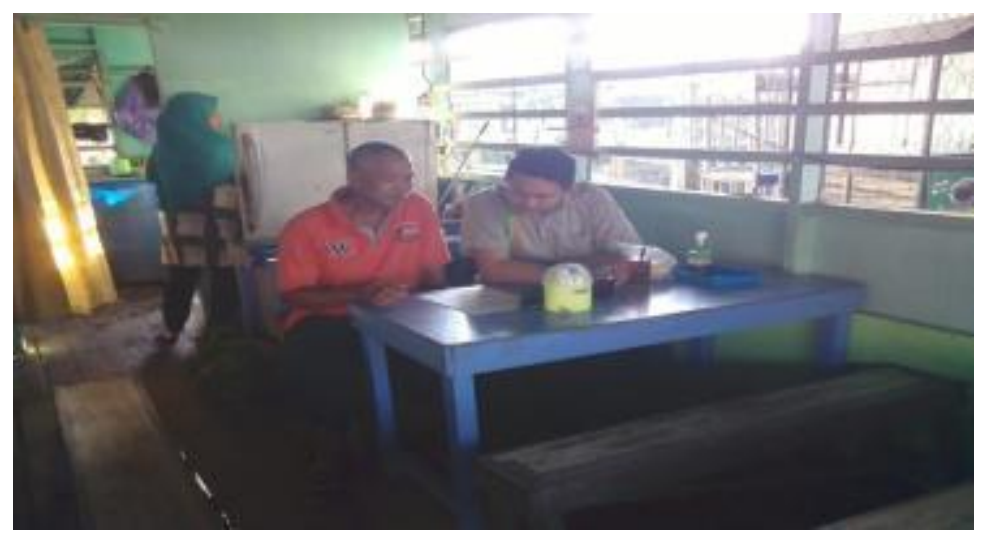

Gambar 8. Pembinaan lanjutan untuk pembuatan business plan

\section{Evaluasi Kegiatan}

Dalam rangka menilai hasil kegiatan, maka evaluasi yang dilakukan antara lain adalah dengan memberikan kuesioner tentang penilaian peserta terhadap pelaksanaan kegiatan yang berkaitan tentang kualitas pembicara, bahan materi, suasana dan prasarana kegiatan,

Berikut ini adalah hasil
penilaian peserta yang telah
dikategorisasi terhadap kinerja
kegiatan.


Tabel 1.

Kategorisasi Kategorisasi Hasil Penilaian Peserta Terhadap Kinerja

Kegiatan

\begin{tabular}{llcccc}
\hline No & Materi & \multicolumn{3}{c}{ Hasil Kategorisasi } & Jumlah \\
\cline { 3 - 5 } & Baik & Cukup & $\begin{array}{c}\text { Kuran } \\
\text { g Baik }\end{array}$ & \\
\hline 1 & Pembicara & 8 & 2 & 0 & 10 \\
2 & Materi & 9 & 1 & 0 & 10 \\
4 & Suasana & 9 & 1 & 0 & 10 \\
3 & Sarana & 7 & 3 & 0 & 10 \\
\hline
\end{tabular}

Sumber : Data Kegiatan, 2018 (diolah)

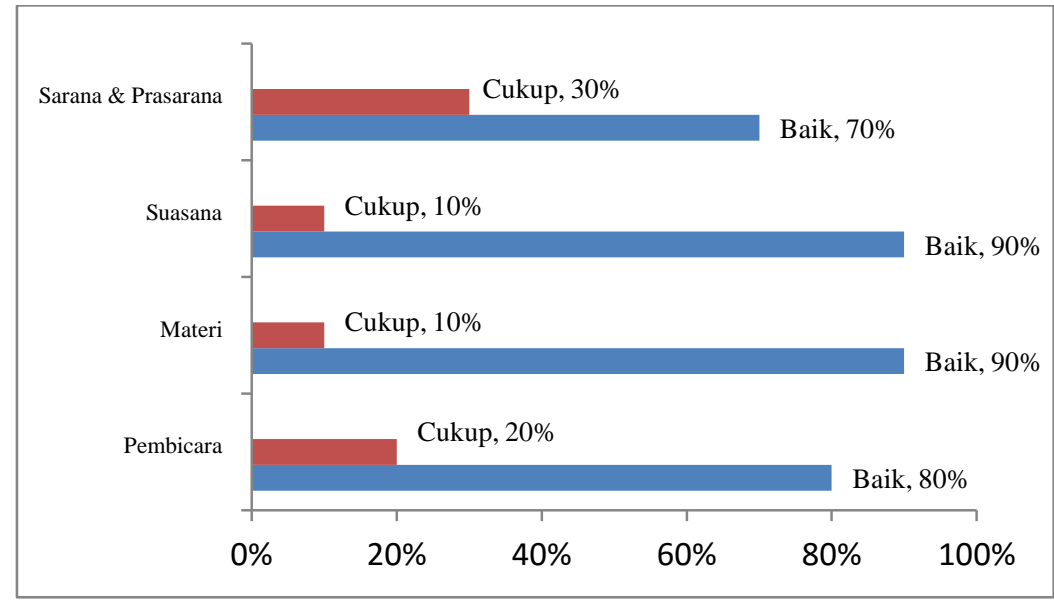

Gambar 9. Perbandingan Skor Penilaian Kegiatan

Berdasarkan hasil penilaian peserta atas kinerja kegiatan, maka dapat dikatakan bahwa pelaksanaan kegiatan pengabdian kepada masyarakat ini secara umum dinilai baik oleh seluruh peserta baik dari segi pembicara, materi, suasana maupun sarana dan prasarana.

\section{Luaran Yang Dihasilkan}

Adapun luaran yang dihasilkan dari kegiatan ini antara lain adalah

1. Publikasi pada jurnal/prosiding pengabdian kepada masyarakat

2. Publikasi pada media online seperti facebook dan website UPT Kewirausahaan Uniska MAB Banjarmasin (Http://ukib.uniska-bjm.ac.id) 
3. Transfer pengetahuan tentang 9 (sembilan) komponen penting dalam penyusunan rencana bisnis dan Keterampilan dalam membuat business plan model canvas untuk perencanaan bisnis UMKM

\section{E. Kendala dan Solusi}

Dalam melaksanakan kegiatan ini kendala yang dihadapi antara lain adalah Adanya perbedaan tingkat pendidikan peserta yang menyebabkan berpengaruh kepada daya serap dan tingkat pemahamannya. Hal ini terlihat bahwa peserta kegiatan yang bisa menyelesaikan business plan secara lengkap dan benar memang memiliki tingkat pendidikan yang lebih baik karena rata-rata sarjana. Sedangkan yang masih memiliki kesulitan dalam membuat business plan umumnya adalah peserta yang hanya memiliki tingkat pendidikan SLTA.

Solusi yang dapat dilakukan adalah, pelaksana melakukan kunjungan ke lokasi atau tempat usaha peserta yang terlihat memiliki pemahaman cukup baik atau mampu menentukan vaaue propositions usahanya namun belum mampu menyelesaikan penyusunan business plan secara lengkap. Hal ini dilakukan agar`pembinaan pasca kegiaatan lebih intensif dan dapat menambah frekuensi pertemuan.

\section{KESIMPULAN DAN SARAN}

\section{Kesimpulan}

Beberapa hal yang dapat disimpulkan atas pelaksanaan kegiatan pengabdian masyarakat ini adalah sebagai berikut:

a) Kegiatan diikuti oleh 10 UMKM kuliner jalanan dikawasan Gatot Subroto Banjarmasin.

b) Hasil pelaksanaan kegiatan diantaranya adalah $30 \%$ peserta mampu membuat business plan model canvas secara baik dan benar, $20 \%$ peserta sudah dapat menentukan komponen value propositions namun masih kesulitan dalam membuat business plan secara keseluruhan dan 50\% peserta masih belum mampu menentukan komponen value propositions dan membuat business plan secara keseluruhan. Untuk peserta yang sudah dapat 
menentukan komponen value propositions, kemudian ditindak lanjuti dengan melaksanakan kunjungan ke lokasi mitra dan dibimbing secara khusus untuk membuat business plan secara lengkap.

c) Hasil evaluasi kinerja kegiatan memberikan hasil mayoritas peserta memberikan penilaian sangat baik kepada kemampuan pembicara dalam menyampaikan materi, isi materi, suasana pelatihan serta sarana dan prasarana.

\section{Saran}

Berdasarkan hasil kegiatan, maka dapat disarankan beberapa hal sebagai berikut

a) Adanya peserta yang kurang memahami penyusunan business plan dapat ditindak lanjuti dengan melakukan kunjungan langsung ke tempat atau lokasi usaha mitra untuk memberikan bimbingan dan pembinaaan dalam hal penyusunan business plan model canvas.

b) Kegiatan masih dapat dilanjutkan dengan metode dan pola pelaksanaan yang berbeda untuk lebih meningkatkan persentase jumlah peserta yang memiliki pemahaman dan kemampuan dalam penyusunan business plan model canvas.

\section{DAFTAR PUSTAKA}

Carvalho, J. M. S, dan Jonker, J. 2015. Creating a Balanced Value Proposition: Exploring the Advanced Business Creation Model. Journal of Applied Management and Entrepreneurship 20(2), 49-64. Doi : $10400.24 / 542$

Kurniawan, D.T. (2012). Konsep Pemberdayaan Pedagang Makanan Kaki Lima Sebagai Potensi Wisata Kuliner (Studi Kasus Pedagang Makanan Kaki Lima di Kawasan Universitas Jember). Prosiding Seminar Nasional Fakultas ekonomi Fakultas Jember : 708-720.

Laforet, S., dan Tann, J. (2006). Innovative characteristics of small manufacturing firms. Journal of Small Business and Enterprise Development, 13(3), 363-380.

Lindgren, P. (2013). Business Model Innovation Leadership: How Do SME's Strategically Lead Business Model Innovation?. International Journal of Business and Management, 7(14), 53-66. Doi:10.5539/ijbm.v7n14p53

Purnomo, B. R. (2017). Competitive Dynamics Pada Usaha Mikro: Analisis Persepsi Kompetitif Pada Usaha Mikro Bidang Kuliner Di Unitomo Street Food Surabaya. Media Mahardhika, 16(1), 1-10. Doi : 10.29062/mahardika.v16i1.2

Osterwalder, A., \& Pigneur, Y. (2010). Business Model Generation: a handbook for visionaries, game 
changers, and challengers. John Wiley \& Sons.

Satrya, D. G. (2010). Wisata Kuliner Sebagai Penyelamat PKL di Kota Surabaya (Culinary Tourism as the Savior of Street Merchants in Surabaya). Neo-Bis, 4(1), 74-90. Doi : 10.21107/nbs.v4i1.578

Sustiana, N. D. 2012. Restoran Kuliner Jalanan Di Bandung. Interior Design, 1(1) : $1-8$.
Swasty, W. (2015). Business Model Innovation For Small Medium Enterprises. The Winners, 16(2), 85-95. Doi 10.21512/tw.v16i2.1561

Vaaland, T. I., and Heide, M. (2007). Can the SME survive the supply chain challenges?. Supply chain management: an International Journal, 12(1),

20-31. 